\title{
Comentário
}

\section{Residência médica: como melhorar sem os três anos?}

Em maio deste ano, a Comissão Nacional de Residência Médica (CNRM) reuniu-se em Brasília com representantes das associações de 35 especialidades médicas, a fim de reformular os requisitos mínimos para o credenciamento de programas de residência médica. Nesse encontro, há muito esperado, a Associação Brasileira de Psiquiatria (ABP) encaminhou suas sugestões, derivadas de um grupo de trabalho e de uma enquete nacional realizada junto a todos os coordenadores de programas e professores titulares de psiquiatria. ${ }^{1}$

Atualmente, 47 programas de residência em psiquiatria estão credenciados pelo CNRM. Pouco mais que a metade dos serviços e $72 \%$ das vagas encontram-se no Sudeste (Tabela). Até há pouco, esses dados não se obtinham facilmente, e a própria CNRM admite que ainda não tem um cadastro $100 \%$ confiável.

\begin{tabular}{|c|c|c|c|c|c|}
\hline Região & $\begin{array}{c}\text { Total de } \\
\text { programas }\end{array}$ & $\begin{array}{c}\text { Número de } \\
\text { R-1 }\end{array}$ & $\begin{array}{c}\text { Número de } \\
\text { R-2 }\end{array}$ & $\begin{array}{c}\text { Número de } \\
\text { R-3 }\end{array}$ & $\begin{array}{r}\text { Total de } \\
\text { residentes }\end{array}$ \\
\hline Sudeste & 26 & 138 & 135 & 67 & 340 \\
\hline Sul & 10 & 37 & 35 & 11 & 83 \\
\hline Nordeste & 6 & 15 & 15 & - & 30 \\
\hline Centro-Oeste & 5 & 11 & 11 & - & 22 \\
\hline Total & 47 & 201 & 196 & 78 & 475 \\
\hline
\end{tabular}

A residência médica tem sido reconhecida como uma forma eficiente de treinamento profissional. O primeiro programa surgiu nos Estados Unidos, em 1889, no John's Hopkins Hospital, coordenado por um ícone da cirurgia, William Halsted. ${ }^{2}$ No Brasil, o primeiro programa foi em ortopedia, implantado no Hospital das Clínicas da USP, em 1945. Na área de psiquiatria, os primeiros iniciaram-se no Instituto de Previdência e Assistência ao Servidor do Estado do Rio de Janeiro (Ipase), em 1948, e no Hospital das Clínicas da USP, em 1951. ${ }^{3}$

O Conselho Nacional de Residência Médica foi criado em 1977, e os requisitos mínimos para a residência em psiquiatria foram definidos em 1983 com dois anos de treinamento em três serviços (internação, ambulatório e urgência), um único curso (psicofarmacologia) e dois estágios obrigatórios (neurologia e saúde mental). Todos os presentes ao encontro admitiram: a legislação está defasada, e ainda neste ano deveriam sair as mudanças.

Passado o tempo, ninguém se conformava mais com os antigos critérios, cobrados em porcentagens, um a um, meticulosamente, a cada recredenciamento. Na prática, os programas de residência em psiquiatria foram à frente, introduzindo novos cursos e estágios, à medida que o conhecimen- to e os serviços foram se aperfeiçoando. ${ }^{4}$ Isto ocorreu, por exemplo, na área de interconsulta, que, há dez anos, já era prática corrente em $90 \%$ dos programas e curso obrigatório em $55 \%$ deles. $^{5}$

Não só os programas de residência progrediram; as sociedades médicas também, juntamente com os nomes de suas especialidades (não há consenso entre as denominações do CNRM, Conselho Federal de Medicina e Associação Médica Brasileira). A CNRM gostaria de, junto com essas entidades, padronizar a nomenclatura das especialidades, além de repensar a concessão de certificações (pelo MEC) e de títulos de especialista.

Várias sociedades de especialidades, incluída a ABP, reivindicaram um aumento no número de anos obrigatórios em suas residências. Esse tema esbarrou em pelo menos três ordens de discussões: financiamento, necessidades da sociedade e competência das instituições onde ocorre o treinamento. Há, no país, 17.197 médicos residentes, distribuídos em 356 programas de residência médica. As principais entidades mantenedoras são o Ministério da Saúde (com repasse de verba do SUS), a Fundap (Fundação do Desenvolvimento Administrativo, de São Paulo) e o MEC. Mexer no número de bolsas, que não se alterou nos últimos seis anos, é dificílimo no presente. A alternativa seria o remanejamento do dinheiro, penalizando as bolsas concedidas a anos "opcionais" e reduzindo o número de vagas de ingresso.

O clima presente no encontro parecia preparar a continuidade dos dois anos obrigatórios, ao contrário da sugestão da ABP (três anos) e do que existe na maioria dos países onde há residência em psiquiatria (só para dar um exemplo, a Argentina prepara-se para o quarto ano obrigatório). Além das dificuldades referentes ao financiamento, representantes da CNRM referiram-se a diferenças existentes entre os programas: nem todos seriam competentes para prolongar com o novo e com a devida qualidade. Houve, também, a ponderação de que a sociedade não poderia aguardar um "superespecialista" que passasse muito tempo na residência médica... Por tudo isso, será difícil ver, numa nova resolução oficial, a residência em psiquiatria sendo cumprida em três anos obrigatórios.

Outras sugestões levadas pela ABP têm mais chances de ser encampadas pela CNRM: seleção em duas fases (eliminatória e classificatória); cinco cursos obrigatórios (psicopatologia, psiquiatria clínica, psicofarmacologia e outras terapias biológicas, psicoterapia, desenvolvimento humano); estágios obrigatórios (ambulatorial, incluindo serviço extrahospitalar; internação; emergência; interconsulta; neurolo- 
gia); avaliação ao final de cada estágio (conhecimento, habilidades, atitude).

Pelo menos três anos de residência são necessários para formar um psiquiatra. É o que a ABP reivindica, apoiada por $78 \%$ dos coordenadores de programas de residência e por professores titulares de psiquiatria. Se isso não for aprovado, ter-se-á que superar o paradoxo de aumentar o conteúdo teórico dentro da mesma car-

\section{Referências}

1. Associação Brasileira de Psiquiatria. Documento traz sugestões para aperfeiçoar residência médica. Psiquiatria Hoje, ano $21, \mathrm{n}^{\circ} 5$; 1999. p. 9.

2. Nogueira-Martins LA. Residência médica: um estudo prospectivo sobre dificuldades na tarefa assistencial e fontes de estresse [Tese de Doutorado]. São Paulo: Unifesp/Escola Paulista de Medicina. São Paulo; 1994. ga horária (pois 80-90\% do tempo deverão continuar dedicados à assistência) e de treinar bem, em novas práticas e estágios a mais, um profissional competente. Tudo isso, em dois anos!

Neury José Botega

Departamento de Psicologia Médica e Psiquiatria da Faculdade de Ciências Médicas da Unicamp

3. Uchôa DM. Organização da psiquiatria no Brasil. São Paulo: Servier; 1977.

4. Calil LC, Contel JOB. Estudo dos programas de residência médica em psiquiatria do Estado de São Paulo no ano de 1993. Rev Bras Psiquiatr 1999;21:139-44.

5. Botega NJ. Residência de psiquiatria no hospital geral: uma enquete nacional. J Bras Psiq 1991;40:419-22. 